\title{
Assessment of worker safety in a pharmaceutical industry using FMEA
}

\author{
Tahera Yesmin*, M. Ahsan Akhtar Hasin and Farhana Afreen Proma
}

Department of Industrial and Production Engineering, Bangladesh University of Engineering and Technology (BUET), Dhaka-1000, Bangladesh

\begin{tabular}{l}
\hline C H R O N I C L E \\
\hline Article history: \\
Received June 2, 2012 \\
Received in revised format \\
28 October 2012 \\
Accepted 30 October 2012 \\
Available online \\
November 42012 \\
\hline Keywords: \\
Failure Mode and Effect Analysis \\
(FMEA) \\
Good Manufacturing Practice \\
(GMP) \\
Risk analysis \\
Risk matrix \\
Tablet manufacturing \\
Worker safety
\end{tabular}
A B S T R A C T

\begin{abstract}
Safety is a relative quantity that is a function of the situation in which it is measured. This research has been conducted in a well established pharmaceutical company in Bangladesh practicing GMP (Good Manufacturing Practice), which has a tablet manufacturing facility. Tablet manufacturing comprises a number of manufacturing activities and machineries. Each of these activities, requiring amalgamated interaction of man, machine, equipment and environment has the potential of producing unforeseen hazards. Therefore, analysis of risk to assure worker safety is not only necessary here, it is also important to use an appropriate tool that can incorporate all the risk- producing parameters. The research work conducted here using a very effective tool named Failure Mode and Effect Analysis (FMEA), consisted of observing the works at different sections, breaking them down into sequential steps, noting the surrounding variables of each task, and using these data to perform risk analysis to find out the most hazardous works for the workers.
\end{abstract}

\section{Introduction}

In a pharmaceutical company, quality assurance and elimination of risks for the workers while manufacturing the products are considered as the prime issues to be concerned. Any pharmaceutical company performing under the guidance of Good Manufacturing Practice (GMP) is alarmed to make its environment hazard free to achieve the ultimate goal of a profitable organization. In the regulation of GMP, it is clearly stated that the organizations should have the continuous and systematic effort to reduce risks of the procedures and environment for the workers (Sharp, 2005).

Hazardous work creates major accidents and disasters in the organizations. Historically, safety was always referred to the machinery as it served to keep the production line operating (Gloss \& Wardele, 1984). It was never an issue of analysis to find whether the working procedures and work environment are creating any risks for the workers or not and workers were rarely considered. An 
organization is only successful when it can keep the workplace free from physical as well as mental hazards. The primary objective of this paper is to analysis the risks of the working procedures and work environment to the workers with the help of Failure Mode and Effect Analysis (FMEA). Failure Mode and Effect Analysis is widely used for assuring the safety, reliability and quality of products and processes. James (1998) stated that a useful aspect of FMEA technique is the fact that it can be applied with equal effect to use either a product design or a process design. When this technique is used on a product design, each subsystem, subassembly and part is examined individually, and analyzed for potential failure modes, which would prevent proper function of the component. When used on a process, each step in the process is examined and analyzed for what could go wrong at that step to produce non-conforming output, or to cause a processing problem at a step downstream.

This paper tries to find the hazards of the workers while manufacturing tablet in a pharmaceutical company. This study also finds the hazardous work environment for the worker. Then a risk matrix has been built to ease the findings on the basis of FMEA. This paper is organized as follows: section 3 describes the methodology of performing the study, section 4 shows the results and section 5 is about the conclusion.

\section{Literature Review}

Pharmaceutical companies are always concerned with the quality as well as the safety issues. There are a number of regulations to ensure the safety and quality of pharmaceutical companies as they deal with sensitive and toxic materials, which lead to the adverse health hazards for the pharmaceutical workers. However, most of the times, they are concerned with the risk assessment or quality assurance of the products but they do not care about the workers. Gujral et al. (2007) performed Monte Carlo simulations to find the final probability of quality of the final products. Very few but worker oriented researches on pharmaceuticals were conducted also. Binks (2003) studied the approaches taken by the pharmaceutical companies for identifying and communicating potential adverse health effects that may result from workplace exposure and setting control limits for exposure. In another research by Kipping (2007), importance on ergonomically risk assessment was accredited as pharmaceutical companies have a trend not to change the equipments and production facilities for a long time.

In this paper the, FMEA is the prime tool to find the risks of the working procedures and environment on the workers in a pharmaceutical company. Failure Mode and Effect Analysis (FMEA) is accepted as a systematic method of identifying and preventing product and process oriented problems. FMEAs are carried back from the United States military procedures MIL-P-1629 (1949). Now it has become a key tool to improve safety, especially in the chemical processing industries. FMEA is a very simple tool to find the failures in processes, products, and designs. Bongiorno (2001) provided a basic overview on the procedures of FMEA. Mcdermott et al. (2009) described a detail technique for performing FMEA as well as showed that FMEA is an integral part of ISO 9000, which is family of standards for quality management system. According to them FMEA is an important factor of ISO/TS 16949 which takes ISO 9001 one step further with an emphasis on a process approach.

Though FMEA was first successfully used in aerospace industries in mid 1960s, many studies have now been conducted to assess the risks using FMEA in different industries. Layzell and Ledbetter (1998) used FMEA to reduce the risks of failures in the cladding systems. Cassanelli et al. (2006) used FMEA for the risk assessment in the design phase of an electric motor control system for vehicle HVAC. FMEA can widely be used in the project risk management. Carbone and Tippett (2004) used FMEA in a customized way to find the risks of a project. Scipioni et al. (2002) used FMEA along with HACCP to assure product quality as a mean to improve operational performance of the production cycle. FMEA was also used for the risk assessment of the processing of ready to eat vegetables (Varzakas \& Arvanitoyannis, 2008). However most of the researchers used FMEA to find 
the risks of failure of a product in the design stage, failure of a system or even a project. FMEA is used here to find out the hazards or risks of a process and work environment on the workers who are constantly in the contact of that process and environment. FMEA is performed in three phases. Phase one: Failure finding, Phase two: Failure evaluation, and Phase three: Measurement to eliminate failures.

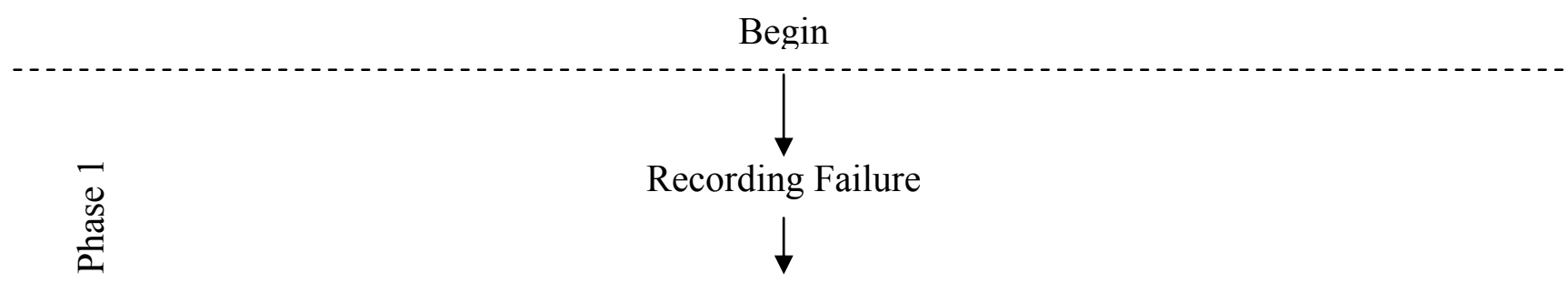

Finding Failure Implication

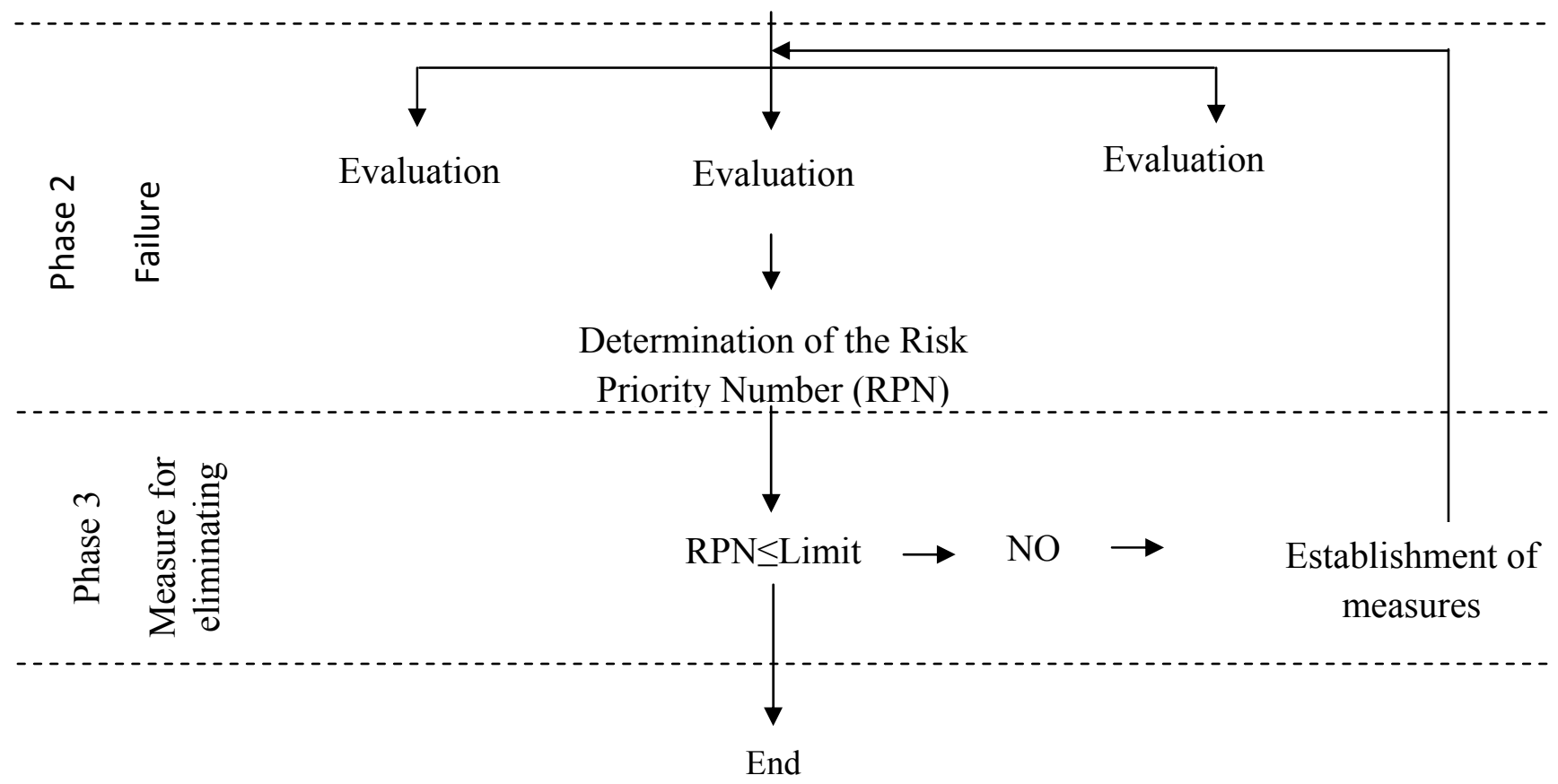

Fig. 1. FMEA flowchart

In phase II, the main task is to determine the value of Risk Priority Number (RPN), which is the multiplication of probability of occurrence $(\mathrm{O})$, probability of severity $(\mathrm{S})$, probability of detection (D) which is shown is the Eq. (1).

$\mathrm{RPN}=$ Occurrence $(\mathrm{O}) \times$ Severity $(\mathrm{S}) \times$ Detection $(\mathrm{D})$

Based on the details of Mcdermott et al. (2009) the values of occurrence (or probability), severity (or impact) and detection have been set which are compatible to the system studied. Then these three values are multiplied to find the RPN (Risk Priority Number) a limit for the RPN is fixed before that. After calculating the RPN number a comparison between the calculated values with limit value of RPN is computed to distinguish which works are the hazardous for the workers.

\section{Methodology}

This research has been conducted in one of the renowned pharmaceuticals of Bangladesh name which is well known for practicing valuable aspects of GMP (Good Manufacturing Practice). Before analyzing the research a brief description about the case and the manufacturing process of the company is given in the following section. 


\subsection{The case}

The respective pharmaceutical company manufactures a number of medicines of seven different types include tablet, capsule, syrup, ointment, powder for suspension injections, and oral saline. Each type of product is manufactured in separate regions to avoid the contamination and to ensure the quality. Among all of the types this study has been accomplished on tablet manufacturing section. This section has been chosen as it is comprised of many difficult activities to perform the procedures step by step and involves a lot of worker functions.

\subsection{Approach to solve}

As stated above that FMEA works on three phases. To accomplish the first phase, which is failure finding, the main task is to identify and to separate the main sections which are needed to manufacture a tablet. There are mainly five sections to manufacture a complete tablet, as follows:

i. Wet Mass mixing, where all the ingredients are mixed together.

ii. Fitz-mill and drier section where the granular form of the ingredients are made and they are dried if needed.

iii. The third section of the procedure of manufacturing a tablet is blending, where all the different ingredients are blended together for a certain time to attain the certain aspect of mixture of the ingredients.

iv. The fourth section is compression, where the blended materials are pressurized and

v. The fifth section is coating to coat the tablet with solutions if needed.

To complete the first phase each stage has been studied individually and the breakdown of all the steps involved in each stage including cleaning is performed in a small detail to find the risky steps, which are marked among all based on the historical data and survey. For the second phase of FMEA which is failure evaluation the customized limit of probability of occurrence $(\mathrm{O})$, probability of severity(S) and probability of detection (D) have been set to calculate the Risk Priority Number which is the multiplication of these three. Table 1, Table 2 and Table 3 respectively show the values set for different categories of $\mathrm{O}, \mathrm{S}$, and $\mathrm{D}$ for this research.

\section{Table 1}

Probability of Occurrence $(\mathrm{O})$

\begin{tabular}{lc}
\hline Probability of Occurrence & Evaluation \\
\hline Improbable: The failure occurs less than once a year & 1 \\
Low :The failure occurs at most three times a year & 2 \\
Moderate :The failure occurs 6 times a year & 3 \\
High: The failure occurs repeatedly & 4 \\
\hline
\end{tabular}

\section{Table 2}

Probability of Detection (D)

\begin{tabular}{lc}
\hline Probability of Detection & Evaluation \\
\hline Accident obvious but can be avoided easily & 1 \\
Accident obvious, can be avoided when moderate careful & 2 \\
Accident obvious, can be avoided when very careful & 3 \\
Accident cannot be avoided & 4 \\
\hline
\end{tabular}

The table of probability of severity (S) is composed based on historical data of accidents. There has been a detail survey to find out the types of injuries occurred on the production floor of tablet manufacturing. Then the risks are ranked based on the severity. The severe the injury, the higher the ranking is. Using Table 1-3, the values for $\mathrm{O}, \mathrm{S}$ and $\mathrm{D}$ are determined for each risky activity of each section of tablet manufacturing. Then the RPN value is calculated. To accomplish the third phase of FMEA the calculated RPN are compared with the allowable limit of RPN set by us. If the calculated 
RPN for any step of work is above the limit, and then that step or work environment is considered as hazardous or risky for the workers. Thus the most risky stage for the workers has been determined.

\section{Table 3}

Probability of Severity (S)

\begin{tabular}{l}
\hline \multicolumn{1}{c}{ Severity in terms of injury } \\
\hline i. Strain and sprain \\
Pull, hurt, twist etc can happen while loading or unloading materials \\
ii. Fatigue and Muscle pain \\
Happens for loading materials repeatedly in any elevated or lower heighten place \\
iii. Collision with haphazard material \\
It can happen when moving with trolleys in a place when drums, boxes etc. are disorganized. \\
iv. Slip on the Wet-Slippery floor \\
While cleaning or making paste, water is scattered on the floor. \\
v. Sweating \\
vi. Titling/ falling \\
Tilting/falling can occur when there is a need to climb up bad conditioned stairs \\
vii. Burning \\
viii. Laceration \\
Small cut \\
ix. Suffocation \\
x. Inhaling particles \\
xi. Bruise \\
xii. Amputation of any part of the hand \\
xiii. Repeated laceration
\end{tabular}

\subsection{Data Generation}

To carry out the risk assessment by a quantitative method which is FMEA, at first the breakdown of all the activities of the above stated five stages are executed. Here, the breakdown of the Wet-mass section is given below

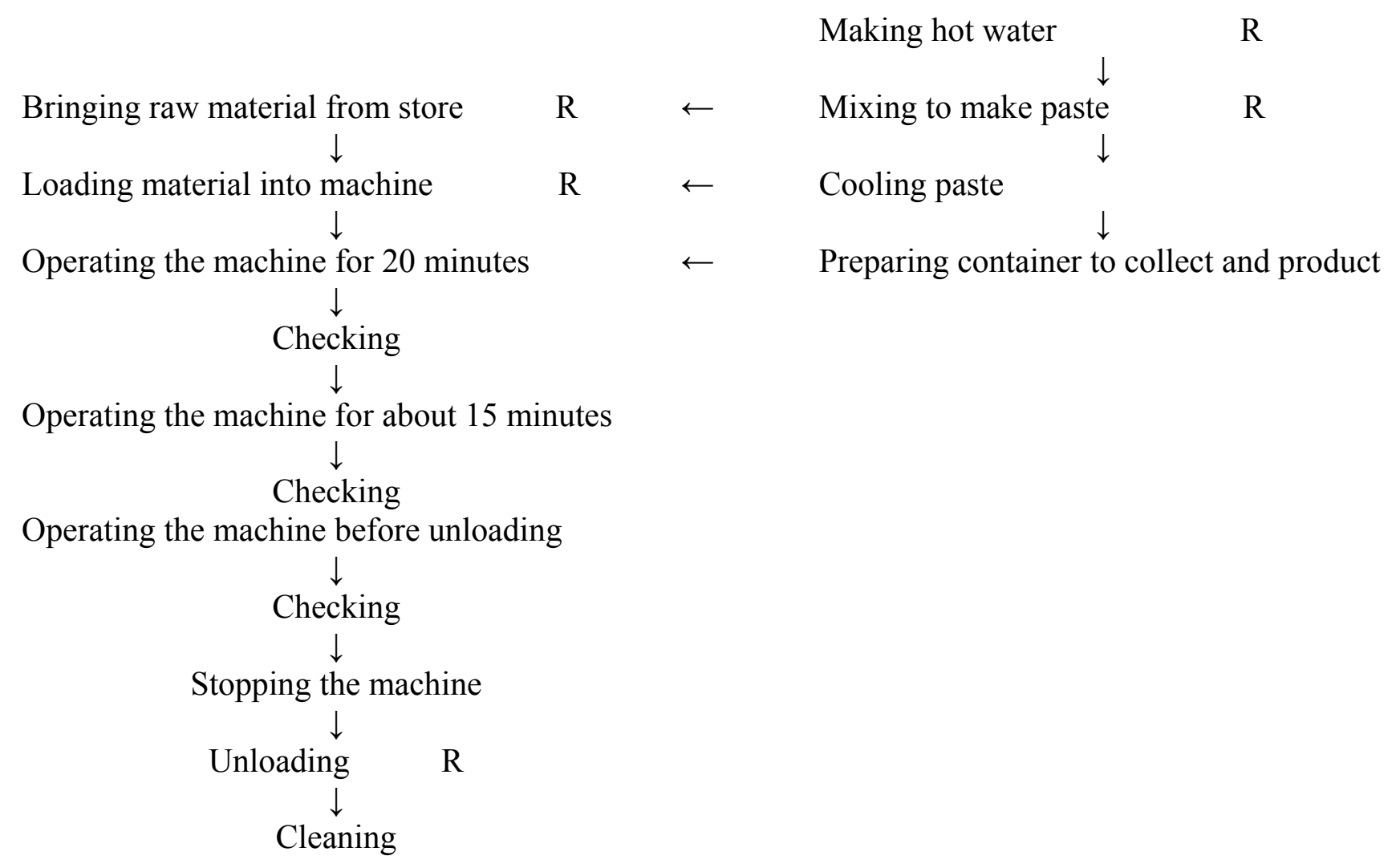

Fig. 2. Work break down for wet mass mixing 
It is already mentioned that wet mass mixing is a section where all the raw materials are mixed together if they need any water as the ingredient. To complete the work of wet mass mixing, it involves many steps. Among them, not all the steps are risky. The risky steps are figured out based on survey and historical data and only those steps are considered for the analysis. The risky steps have been separated on flow chart by denoting them with ' $R$ '.

\subsection{Data Calculation}

In this step the value of $\mathrm{O}, \mathrm{S}$ and $\mathrm{D}$ for each of the risky steps for each of the five stages of table manufacturing are determined. Then the multiplication of these three values which is RPN, is calculated. The calculation of RPN for the wet mass mixing section is provided in details in the following table 4 .

\section{Table 4}

Calculation of RPN for Wet Mass Mixing

\begin{tabular}{|c|c|c|c|c|c|}
\hline \multicolumn{6}{|c|}{ Risk Assessment Of Working Procedures for the workers } \\
\hline \multicolumn{2}{|r|}{ Risk assessment of activities } & \multirow{2}{*}{$\begin{array}{l}\text { Consequences } \\
\text { a. Fatigue }\end{array}$} & \multicolumn{2}{|c|}{ RPN } & \multirow{3}{*}{$\begin{array}{l}\text { Maximum RPN } \\
\text { for the activity } \\
16\end{array}$} \\
\hline \multirow[t]{2}{*}{1.} & \multirow[t]{2}{*}{ Bringing in Raw material } & & $4 \times 1 \times 4$ & 16 & \\
\hline & & b. Strain and sprain & $2 \times 1 \times 2$ & 4 & \\
\hline 2. & Boiling water in P- kettle & a. Burning & $3 \times 2 \times 2$ & 12 & 12 \\
\hline 3. & Mixing to make paste & a. Fatigue and muscle pain & $4 \times 1 \times 4$ & 16 & 16 \\
\hline \multirow[t]{2}{*}{4.} & \multirow{2}{*}{$\begin{array}{l}\text { Loading material into the } \\
\text { machine }\end{array}$} & a. Fatigue and muscle pain & $4 \times 1 \times 4$ & 16 & \multirow[t]{2}{*}{16} \\
\hline & & b. Strain and sprain & $3 \times 1 \times 2$ & 6 & \\
\hline \multirow[t]{2}{*}{5 . } & \multirow[t]{2}{*}{ Unloading the end product } & a. Strain and sprain & $3 \times 1 \times 2$ & 6 & \multirow[t]{2}{*}{24} \\
\hline & & b. Inhaling particles & $4 \times 3 \times 2$ & 24 & \\
\hline \multirow[t]{3}{*}{6 . } & \multirow[t]{3}{*}{ Cleaning } & a. Inhaling particles & $4 \times 3 \times 2$ & 24 & \multirow[t]{3}{*}{24} \\
\hline & & b. Fatigue and muscle pain & $4 \times 1 \times 4$ & 16 & \\
\hline & & c. Strain and sprain & $3 \times 1 \times 2$ & 4 & \\
\hline \multirow[t]{4}{*}{7.} & \multirow{4}{*}{$\begin{array}{l}\text { Cleaning and operation of } \\
\text { multimill* }\end{array}$} & a. Laceration & $2 \times 2 \times 3$ & 12 & \multirow[t]{4}{*}{30} \\
\hline & & b. Amputation & $2 \times 5 \times 3$ & 30 & \\
\hline & & c. Repeated laceration & $2 \times 5 \times 3$ & 30 & \\
\hline & & d. Inhaling particles & $4 \times 3 \times 2$ & 24 & \\
\hline \multicolumn{6}{|c|}{ Risk assessment of work-environmental factors } \\
\hline 1. & $\begin{array}{l}\text { Powdered material spread on } \\
\text { floor }\end{array}$ & Slipping & $3 \times 1 \times 1$ & 3 & 3 \\
\hline 2 & Wet floor & Slipping & $3 \times 1 \times 1$ & 3 & 3 \\
\hline 3. & $\begin{array}{l}\text { Unorganized containers in } \\
\text { the room }\end{array}$ & Collision & $3 \times 1 \times 2$ & 6 & 6 \\
\hline
\end{tabular}

According to Table 4, the risk is measured for both the working procedures and work environment on the workers. One risky step may have many bad consequences. RPN for all the consequences are calculated and among them the consequences with highest RPN has been chosen.

\section{Results}

\subsection{Impact of RPN limit to the risky steps}

The RPN value is calculated at a scale of 80 , where $\mathrm{O}=4, \mathrm{~S}=5$ and $\mathrm{D}=4$. To consider the safe value of each step, limit of the value of Risk priority number (RPN) is set to 12 (15\% of 80$)$. This limit is set after analyzing the RPN numbers of all the steps in details. A detail study has been executed to see this safe RPN limit. According to this safe value of RPN which ever step crosses this limit will consider as risky step and therefore, measures have to be taken for that step. 
So if RPN $>12$, then the step is risky, which implies that there must be sufficient measures taken to reduce the step. Therefore, the step needs corrective measures. After the study of all five sections of tablet manufacturing it is clear that there are 28 steps which are risky for the workers. All the RPN values are plotted on a graph and the following result is found, The graph clearly shows that among 28 steps only 10 steps have RPN value less than or equal to 12 , which implies though there are 28 risky steps but among them only 18 steps should be considered hazardous for the workers, and measures should be taken on those steps.

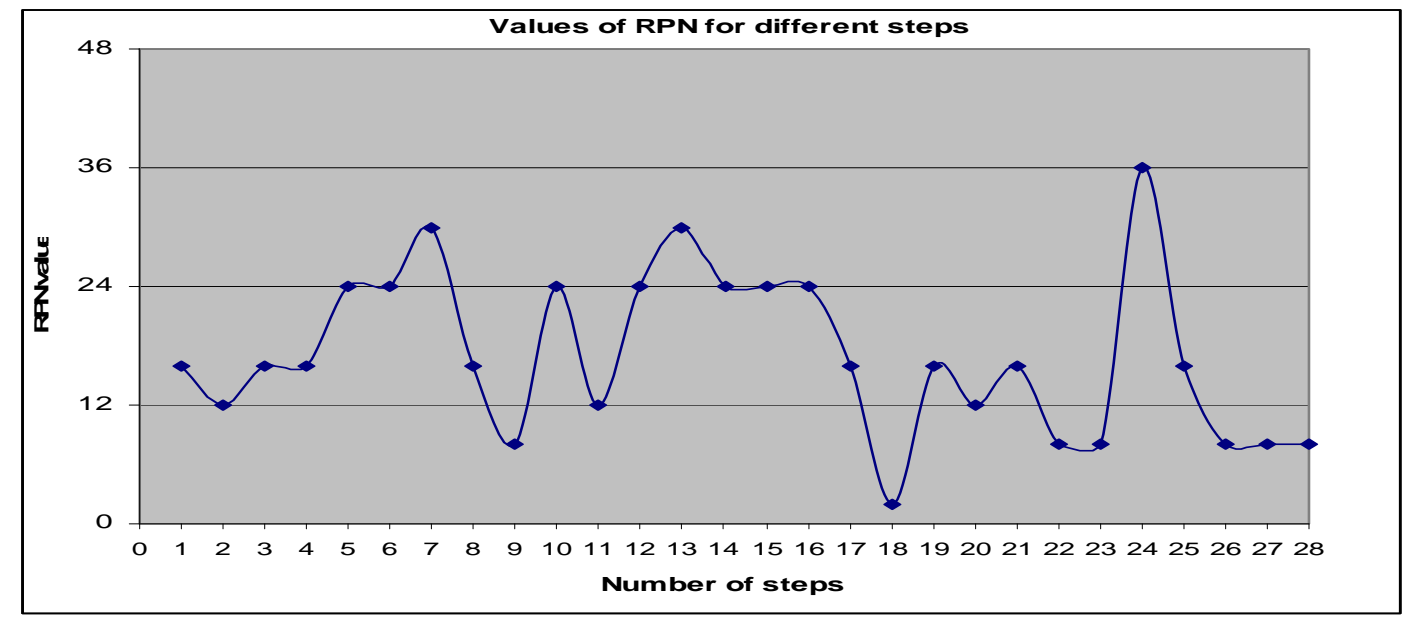

Fig. 3. Scatter diagram to shows the values of RPN for all the steps

\subsection{Determination of percentage of risky steps for each section of tablet manufacturing}

The number of risky steps of each section has been accumulated in the following table. Table 5 shows the percentage of risky steps in comparison to the total steps of every section as well as shows the number of risky steps whose value exceeds the safe RPN limit among them.

\section{Table 5}

Calculation for the percentage of risky steps of every section

\begin{tabular}{|c|c|c|c|c|c|c|c|}
\hline \multirow{2}{*}{ 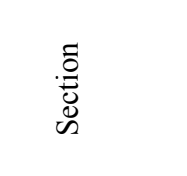 } & \multirow{2}{*}{$\begin{array}{l}\text { U. } \\
\dot{0} \\
\dot{0}\end{array}$} & \multirow{2}{*}{ 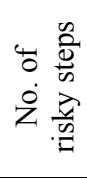 } & \multirow{2}{*}{ 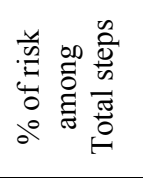 } & \multicolumn{2}{|c|}{$\begin{array}{c}\text { Risky steps without corrective } \\
\text { action, } \\
(\mathrm{RPN} \leq 12)\end{array}$} & \multicolumn{2}{|c|}{$\begin{array}{c}\text { Risky steps needed corrective } \\
\text { action } \\
(\mathrm{RPN}>12)\end{array}$} \\
\hline & & & & Number & & $\begin{array}{l}\text { Number } \\
\text { of steps }\end{array}$ & $\%$ \\
\hline 1.Wetmass & 14 & 6 & 42.85 & 1 & 16.67 & 5 & 83.33 \\
\hline 2.Fitzmill & 8 & 6 & 75 & 2 & 33.33 & 4 & 66.67 \\
\hline 3.Drier & 8 & 4 & 50 & 0 & 0 & 4 & 100 \\
\hline 4. Blender & 18 & 7 & 38.88 & 3 & 42.85 & 4 & 52.14 \\
\hline 5.Compressor & 11 & 4 & 36.36 & 3 & 75 & 1 & 25 \\
\hline 6.Coating & & & & thas no ri & & & \\
\hline
\end{tabular}

Table 6 shows the value of the environmental impact of each section on the workers in percentage.

\subsection{Ranking of Risky Section}

Based on all the above calculations and results the following final result is obtained and they are shown in Table 7. Based on the results among all the five sections Fitz-mill is having the most risky steps but Drier is having the greatest percentage of risky steps which need corrective measures. Along with this, Drier also needs corrective actions for its environmental condition to make it safe for the workers. 


\section{Table 6}

Percentage environmental impact on workers

\begin{tabular}{|c|c|c|c|c|c|}
\hline \multirow[t]{2}{*}{ Section } & \multirow[t]{2}{*}{ Number of environmental impacts } & \multicolumn{2}{|c|}{$\begin{array}{l}\text { No corrective measures } \\
\text { needed } \quad(\mathrm{RPN}<12)\end{array}$} & \multicolumn{2}{|c|}{$\begin{array}{c}\text { Corrective } \\
\text { measures needed } \\
(\mathrm{RPN}>12)\end{array}$} \\
\hline & & No. & $\%$ & No. & $\%$ \\
\hline 1.Wetmass & 3 & 3 & 100 & 0 & 0 \\
\hline & 4 & & & & \\
\hline $\begin{array}{l}\text { 2. Fitzmill } \\
\text { 3.Drier }\end{array}$ & $\begin{array}{l}\text { Note: Fitzmill \& drier are situated in } \\
\text { one room }\end{array}$ & 2 & 50 & 2 & 50 \\
\hline 4. Blender & 1 & 1 & 100 & 0 & 0 \\
\hline 5. Compressor & 2 & 2 & 100 & 0 & 0 \\
\hline 6. Coating & 0 & 0 & 0 & 0 & 0 \\
\hline
\end{tabular}

Table 7

Ranking of risky section for tablet manufacturing

\begin{tabular}{lcc}
\hline Section & $\begin{array}{c}\text { Ranking of risky activities } \\
\text { according to RPN }>12\end{array}$ & $\begin{array}{c}\text { \% of Risky steps needed corrective } \\
\text { action }\end{array}$ \\
\hline Drier & 1 & 100 \\
Wetmass & 2 & 83.33 \\
Fitzmill & 3 & 66.67 \\
Blender & 4 & 52.14 \\
Compressor & 5 & 25 \\
Coating & 6 & 0 \\
\hline
\end{tabular}

\section{4 Risk Ranking Table}

A risk-ranking table can be formulated from the above results. According to Reliasoft (2007) risk ranking tables is used to assist the decision-making process. These tables will typically identify whether corrective action is required based on some combination of Severity, Occurrence, Detection and/or RPN values. Table 8 is formulated for this case where severity is placed horizontally and Occurrence vertically.

\section{Table 8}

Risk Ranking Table

\begin{tabular}{|c|c|c|c|c|c|c|}
\hline $\mathrm{O}$ & $\mathrm{S}$ & 1 & 2 & 3 & 4 & 5 \\
\hline 1 & & $\mathrm{~N}$ & $\mathrm{~N}$ & $\mathrm{~N}$ & $\mathrm{~N}$ & $\mathrm{~N}$ \\
\hline 2 & & $\mathrm{~N}$ & $\mathrm{~N}$ if $\mathrm{D}<4$ & $\mathrm{~N}$ if $\mathrm{D}<3$ & $\mathrm{~N}$ if $\mathrm{D}<2$ & $\mathrm{~N}$ if $\mathrm{D}<2$ \\
\hline 3 & & $\mathrm{~N}$ & $\mathrm{~N}$ if $\mathrm{D}<3$ & $\mathrm{~N}$ if $\mathrm{D}<2$ & $\mathrm{~N}$ if $\mathrm{D}<2$ & $\mathrm{C}$ \\
\hline 4 & & $\mathrm{~N}$ if $\mathrm{D}<4$ & $\mathrm{~N}$ if $\mathrm{D}<2$ & $\mathrm{~N}$ if $\mathrm{D}<2$ & $\mathrm{C}$ & $\mathrm{C}$ \\
\hline
\end{tabular}

The letters and numbers inside the table indicate whether a corrective action is required for each case.

- $\quad \mathrm{N}=$ No corrective action needed.

- $\mathrm{C}=$ Corrective action needed.

- $\quad \mathrm{N}$ if $\mathrm{D}<\#=$ No Corrective action needed if the Detection rating is less than the given number.

For example, according to the risk ranking table, if Severity $=2$ and Occurrence $=2$, then corrective action is required if Detection $=3$ or higher. If Severity $=5$, occurrence $=3,4$ then corrective action is always required. 


\section{Conclusion}

By using FMEA for industries like pharmaceutical, we can easily identity the risky steps and hazardous environment which hampers the efficiency and safety of the workers. Workers are the main asset to any organization. If they are safe and sound, the organization can be termed as successful. FMEA is a very useful tool for the industries to measure the risks as well as to prioritize the risky works. In our case, we have measured that 'Drying section' is the most hazardous as it involves the greatest number of risks. On the other hand Coating section is established as a hazard free section after the calculation of FMEA.

However, it can be easily concluded that FMEA is a very effective tool but before carrying out to FMEA, the participants must be trained in its application. In the initial implementation of FMEA, the company should not be rushed. The staff must first become familiarized with the method and practice it before performing. Thus if FMEA is successfully implemented it can identity not only the risks but also it can reduce the cost of any project or any organization.

\section{Acknowledgment}

The authors would like to thank the anonymous referees for constructive comments on earlier version of this paper.

\section{References}

Binks, S. P. (2003) Occupational toxicology and the control of exposure to pharmaceutical agents at works. Occupational Medicine, 53 (6), 363-370.

Bongiorno, J. (2001) Use FMEAs to improve your product development process. PM Network, 15(5), 47-51.

Carbone, T. A. \& Tippett, D. D.(2004) Project Risk Management using the Project Risk FMEA. Engineering Management Journal, 16(4), 28-35.

Cassanelli, G., Mura, G., Fantini, F., Vanzi M. \& Plano, B.(2006) Failure Analysis-assisted FMEA. Microelectronics and Reliability, 46(9-11), 1795-1799.

Gloss, D. S. \& Wardele M.G. (1984). Introduction to safety Engineering. John Wiley and Sons, New York.

Gujral, B., Stanfield, F. \& Rufino, D. (2007) Monte Carlo simulation for risk analysis for in pharmaceutical product design. Proceedings of the 2007 crystal ball user conferences.

James, E.B. (2008) Risk analysis: Two tools you can use to assure product safety and reliability. http://www.1stnclass.com/risk analysis.htm. Accessed March 3, 2007.

Kipping, J. A. (2007) Ergonomic risk assessments within a pharmaceutical company. Proceedings of the $39^{\text {th }}$ Nordic Ergonomic Society Conferences.

Layzell, J. \& Ledbetter, S.(1998) FMEA applied to cladding systems-reducing the risk of failure. Building research and Information, 26(6), 351-357.

Mcdermott, R.E., Mikulak, R.J., \& Bearegard M.R.(2009) The Basics of FMEA. CRC Press, New York

Reliasoft.(2007) Examining Risk Priority Numbers in FMEA, 4(1). http://xfmea.reliasoft.com .Accessed February 23, 2007.

Sharp, J (2005) Good pharmaceutical manufacturing practice: rationale and compliances. CRC press, New York.

Scipioni, A., Saccarola, G., Centazzo, A. \& Arena, F. (2002) FMEA methodology design, implementation and integration with HACCP system in a food company. Food Control, 13(8), 495-501. 
Varzakas, T. H. \& Arvanitoyannis, I. S. (2008) Application of failure mode and effect analysis and cause and effect analysis on processing of ready to eat vegetables - part II. International Journal of Food Science and Technology, 44 (5), 932-939. 